and Hospital Epidemiology includes the first SHEA position paper "The HIV-Infected Healthcare Worker," which was coauthored with the Association for Practitioners in Infection Control (APIC) and is being published simultaneously in its journal, American Journal of Infection Control. This is an especially timely and hotly debated topic, given the recently reported episode of possible transmission of the acquired immunodeficiency syndrome (AIDS) in a dental operatory and the resulting proposal by the CDC to revise some of its recommendations.

A second SHEA position paper, on biohazard waste, is tentatively scheduled for publication in early 1991. Dr. William Rutala is chairing the group working on this issue.

Finally, Dr. Robert Sherertz is chairing a task force to develop a position paper on surgical wound infection surveillance. This group includes representation from the Surgical Infection Society, the CDC and SHEA.

\section{SHEA Intervention at HCFA}

Dr. William Scheckler filed the following report: September 13, 1990, I represented SHEA at the Health Care Financing Administration (HCFA) headquarters in Baltimore, Maryland, to address the issue of the HCFA nosocomial infection generic quality screen. The meeting also included representatives of the CDC, APIC, American Hospital Association (AHA), American Medical Association (AMA), American Medical Peer Review Organizations (PROs) and three officials and two staff from HCFA's Health Standards and Quality Review Bureau. Serving as representatives of these other organizations were several colleagues from SHEA: Drs. Walter Hierholzer (AHA), Peter Gross (AMA), Robert Gaynes (CDC) and Jeff Band. We were successful in persuading the HCFA and the PRO to eliminate their "nosocomial infection generic quality screen."

Several events led to this meeting. HCFA contracts with state PROs to evaluate the quality of care received by Medicare patients in acute-care hospitals. In the 1980s, with the help of outside consultants, HCFA identified a number of adverse outcomes or occurrences in patients as "sentinel event indicators" to be assessed by chart review. Over the past two years, HCFA has gotten increasingly specific in its PRO contracts and required all PROs to include HCFA-specified indicators. One of the six general areas was "nosocomial infections." In some states, the presence of a "nosocomial infection" on a chart review was an "automatic quality problem." Some HCFA regions held that such infections were frequently "Severity Level II" problems, meaning medical mismanagement with potential for significant adverse effects on the patient. It was this application that led SHEA board member, Dr. Band, to bring this issue to the board meeting in Atlanta on July 31, 1990. The SHEA board decided to gather more information about the screen, how it was developed and whether any amendments were possible. The problem was presented to Dr. James Mason, assistant secretary of HHS and former director of the CDC, who promised to look into it. Finally, at their own meetings, the PRO organizations also had become aware of a diversity of views as to how this screen was being applied. They reviewed the situation and sent a letter to HCFA on July 24 detailing an expanded and clarified mechanism of applying the generic screen.
At the meeting convened by HCFA on September 13, the representatives from all the organizations agreed that the presence of a nosocomial infection should not be considered a sentinel event and that the screen, as currently configured, should be eliminated. The group agreed that ways should be found to assess quality in the area of infections, not just nosocomial infections, and offered some suggestions. Therefore, the "nosocomial infection" screen will be replaced by one that will be based on current views of infections and that will be managed more readily by the $\mathrm{PRO}$ chart review process.

I am personally convinced that SHEA allowed prompt communication of the problem, appropriate contact at several levels with the federal officials involved and the calling of a meeting where we were able to make our case clear. It is to HCFA's credit that they listened to our arguments and were willing to use our expertise and to consider plausible alternative. So the next time you wonder why you joined SHEA-reread the above!

William E. Scheckler, MD

\section{SHEA-CDC-AHA Course}

The next offering of SHEA's highly popular Infection Control Course for Infectious Disease fellows and for new hospital epidemiologists is scheduled for May 16-19, 1991. As in the past, the course will be cosponsored by the CDC, and this year, for the first time, the course also will be sponsored by the AHA. Current plans are for the course to be held at AHA headquarters in Chicago, Illinois. Look for more details in upcoming issues of the Newsletter. 